\title{
New Bio-Flocculatious Effect and Its Examination
}

\author{
Zoltán Hodai*, Dóra Rippel-Pethő, Géza Horváth, Laszló Hanák, Róbert Bocsi \\ Department of Chemical Engineering Science, University of Pannonia, Institute of Chemical and Process \\ Engineering, Veszprém, Hungary \\ Email:
}

Received 9 April 2014; revised 14 May 2014; accepted 22 May 2014

Copyright (C) 2014 by authors and Scientific Research Publishing Inc.

This work is licensed under the Creative Commons Attribution International License (CC BY). http://creativecommons.org/licenses/by/4.0/

(c) (i) Open Access

\begin{abstract}
Algaetechnology is a significant scope of the international research and developmental work because it's a green technology that reduces the utterance of impurities and works as a renewing energy source. The $\mathrm{CO}_{2}$ from stack gases of the various flows of manufacturing and the nitrogen from certain technical wastewater are necessary for the plants even as algae. The transaction of $\mathrm{CO}_{2}$ with this object and the utilization stand a good chance by hungarian clime with the teamwork from the technical environment. The technology is a new solution in Hungary which eases utterance of the impurities. As a result of our research we expanded alga polities which utilize the $\mathrm{CO}_{2}$ from refinery's stack gas and they grow intensively in the continental clime, too. The critical points of the technology are the concentration of the algae suspension and the extraction because of the high investment and operating costs and high operational time. The algae technology in this direction depends on this step. Our aim is to separate the algae mass faster and more economical from the starter solution. The optimization of the separating operations and technologies takes notice of the environmental and economic aspects.
\end{abstract}

\section{Keywords}

Algaetechnology, Microalgae, Separation, Flocculation, Measurement

\section{Introduction}

The utilization of microalgae carbon dioxide interception is an important area of international research and development. The absorption of certain technological exhaust gases is possible with the photosynthesis of microalgae. The absorption of carbon dioxide can even reach the value of 100 t/ha. C16-C22 esters are formed in certain al-

*Corresponding author. 
ga cells which can be used for the production of biodiesels. This method is thus capable of the production of fuels from renewable sources [1]-[4].

Algae production is the most promising solution amongst the alternatives because of its specific area necessity and high reproduction rate [5]-[8]. Composition of a microalgae cell depends on cultivation parameters. We test available and applicable species at the local climatic conditions. Afterwards microalgae passed the local test might be phased in production.

Research is being carried out in carbon dioxide absorption from technological flows at the Department of Chemical Engineering of the University of Pannonia [9]. The absorption of carbon dioxide and the reduction of the release of other pollutants (wastewater) with microalgae are examined.

The algae technologies that adapt the threwed out impurities to useful materials and because of it ease the stint of utterance get more consideration. In the technical sizes functioning bioreactors can be solution for occlusing of nitrogen oxids because they use the said compounds by photosynthetical alteration of energy with preparation of energy and useful materials.

We planned and built various grower systems in University of Pannonica even as the region of refinery, and through it we researched the turnout of biomass and the algae products as renewing propellant.

The propagation and environmental tolerance parameters have been examined, together with the possibilities to further develop the technology. During the experiments, the whole technological chain has been examined, providing the possibility to optimize the whole of the operational chain.

Research on whole range of algae cultivation and processing is done at the Department of Chemical Engineering at the University of Pannonia. The utilization of algae cultures in experimental photobioreactors is examined, together with the optimization of the operational conditions both for artificial and natural light and with different substrate solution. The various parameters of alga-processing are also determined.

In the focus of our work are the following things, among others: processing and separating operations. We aim to separate the algae from the substrate solution in the most economic and simplest way. Furthermore, we try to define the useful components of algae and their optimal extraction, based on the optimization of techniques of extraction and other economical and environmental aspects.

The harvest can be carried out with microfiltration, ultra filtration, centrifugation, flocculation, with sonochemical techniques, or with any other techniques that are under development [10] [11]. In addition to chemical flocculation, clarification and membrane separation procedures, special attention has been paid to auto flocculation phenomena.

The analytics of the separation experiments: The effect of the flocculants was followed by Particle Charge Detector (PCD) measurements and defined with the clarification experiments. These also make the interpretation of the results difficult (Because of the great amount of experimental data and the complex correlation between them, correlation analysis needed to achieve better understanding). The extent of separated and cleansing was monitored by measuring the extract content and the electrical conductivity of the permeate.

The aim of this paper is to present the tendency of certain special alga species (Chlorella Vulgaris Beij., Scenedesmus Acutus Meyen) towards special autoflocculation techniques.

This new bio-flocculation is a novel approach to autoflocculation, which has been developed at the Institute of Chemical and Process Engineering of the University of Pannonia. The technology is an extension of the phenomenon of autoflocculation.

Our aim is to devise a densification and separation process which has a low energy need and an advantageous operation time.

\section{Autoflucculation}

The algapopulations to react for certain external effects (not exactly defined in the majority cases) clott into flocks and they start the settlement. The root causes are the change of $\mathrm{pH}$ and the seceded salt because of it [12]-[14]. The autoflocculation is worked the most easily with stopping the $\mathrm{CO}_{2}$ feed. By stopping the $\mathrm{CO}_{2}$ feed (with air feed) the slow, small-scale subsidence of algae starts. In this case the role of the vaporized $\mathrm{O}_{2}$, the radiated light, the present nutrient-, and/or metabolism components are still unexplained. Not even the said parameters connection-system's effect for the subsidence.

The cells clott into plants. In the pending settlement and at the end of it both the nutrient uptake, both the energy uptake are hampered [15] [16]. 
Some algaspecies' flocculation-examination, for example the Nannochloropsis Oceanica [17] (sea alga) and an treatise about autoflocculation of the the Scenedesmus [18] species are reviewed. By certain circumstances autoflocculation get started if some other conditions come to them [12]. The bacteria get weighty role in the algae's flocculation and settlement.

Three bacteria: flavobacteria, terrimonas and sphingobacteria are important for the flocculation of the Chlorella Vulgaris [19]. This effect is not exactly defined, says the specialist literature, these examinations are rather bioflocculation than autoflocculation because of the presence of bacteria, buti it can be acceptable as autoflocculatious effect [20].

By some special algaspecies is enough to be mixed for subsidence or even to swim up; but the rearing of them need more attention. During the rearing they hardly or even not tarry homogenious in the nutrient solution [12]. The effect of autoflocculation starts above $\mathrm{pH} 8.5$ as the algacells charges change from negative to neutral.

By using the effect of autoflocculation the suspensio is more easily settleable, filterable or centrifugalable [21]. In this case the settlement is not so energy and money demanding. It's worthy to examinate how can we give rise to it and how can we control it over. If we step up the intensity of autoflocculation it can be more utilizable.

\section{Examinations of Autoflocculation}

On examinations I found that autoflocculation can even start if the amount of the nutrient components is not adequate.

\section{Stop of the $\mathrm{CO}_{2}$ Feed}

From the photo-bioreactors were samples of $500 \mathrm{ml}$ taken out from several species and several reproduction's phases (several lifecycles).

The average velocity of settlement was about $4 \mathrm{~mm} / \mathrm{h}\left(=1.1 \times 10^{-9} \mathrm{~m} / \mathrm{s}\right)$ by the suspensions in the reproduction's phase. For the separation it's unacceptable small value.

During the settlement the under thick slurry layer is long in maturation and rise slowly. In the layer of suspension is the concentration gradient is slick. The scotch of suspension and clear liquid is blunt in the most cases.

\section{Flow Choke with Carbon Dioxide-FCCD}

What we experienced during the work is the newest access of the effect of autoflocculation. It's about the stretching of autoflocculation. The compound what needed settled is saturated with rank $\mathrm{CO}_{2}$. The velocities of settlement are grown (Table 1).

Wholer settlement can be perceptible (Figure 1).

Hence forward the perfusion of rank $\mathrm{CO}_{2}$ through the suspension was built in because in certain cases it made the settlement more intensive.

The program of examination is in Table 2. The value flow of the feeded $\mathrm{CO}_{2}$ is $240 \mathrm{dm}^{3} / \mathrm{h}$ in the gas distributor $\left(15 \mathrm{dm}^{3} / \mathrm{h}\right.$ per bottle).

Defining the index of reproduction was by photometer in case of Flow Choke with Carbon Dioxide (FCCD) samples. The sample in case of need was attenuated to get the absorbance between 1.5 - 2.5.

After it the index of reproduction $(P I)$ comes from the product of attenuation $(H)$ and absorbance $\left(A_{681.5 \mathrm{~nm}}\right)$.

$$
P I=H \times A_{681.5 \mathrm{~nm}}
$$

If the biomass concentration is so high that the absorbance's value is over 2.5; dilution is needed. It should be

Table 1. Comparative of autoflocculations.

\begin{tabular}{lcc}
\hline & \multicolumn{1}{c}{ Applied techniques of autoflocculation } \\
\hline Examinations of settlement with algasolutions in reproduction's phase & Stop the $\mathrm{CO}_{2}$ feed & $3-5$ \\
Average velocity of settlement $[\mathrm{mm} / \mathrm{h}]$ & Flow choke & Stop the $\mathrm{CO}_{2}$ feed \\
Examinations of settlement with algasolutions after reproduction's phase & $4-7$ & Flow choke \\
Average velocity of settlement $[\mathrm{mm} / \mathrm{h}]$ & $15-25$ \\
\hline
\end{tabular}




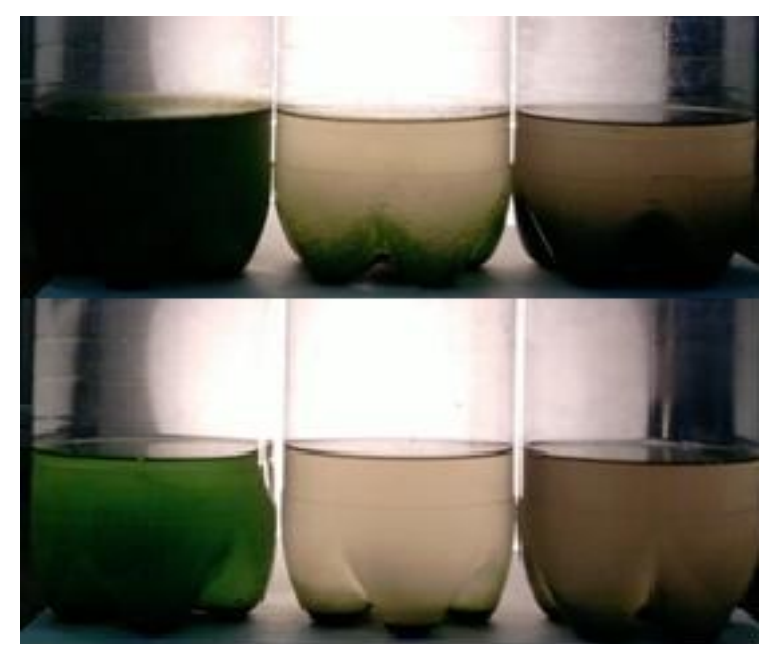

Figure 1. On the picture's upper part is the result of stopping the $\mathrm{CO}_{2}$ feed, on the under part is the result of flow choke with $\mathrm{CO}_{2}$.

Table 2. Comparative of autoflocculations.

\begin{tabular}{ccccc}
\hline Bottle code & Species of alga code & Fill in of alga $\left[\mathrm{dm}^{3}\right]$ & Fill in of nutrient solution $\left[\mathrm{dm}^{3}\right]$ & Lighting \\
\hline 01 & 31 & 1.50 & 0.00 & $\mathrm{~F}$ \\
02 & 31 & 1.50 & 0.00 & $\mathrm{~F}$ \\
03 & 31 & 1.00 & 0.50 & $\mathrm{~F}$ \\
04 & 31 & 1.00 & 0.50 & $\mathrm{~F}$ \\
05 & 31 & 1.00 & 0.50 & $\mathrm{~F}$ \\
06 & 31 & 0.25 & $\mathrm{~F}$ & $\mathrm{~F}$ \\
07 & 31 & 0.25 & 1.25 & $\mathrm{~S}$ \\
08 & 0 & 1.00 & 0.50 & $\mathrm{~S}$ \\
09 & 31 & 1.50 & 0.00 & $\mathrm{~S}$ \\
10 & 0 & 1.00 & 0.50 & $\mathrm{~S}$ \\
11 & 31 & 0.25 & 1.25 & $\mathrm{~S}$ \\
13 & 31 & 0.25 & 1.25 & $\mathrm{~S}$ \\
15 & 31 & 1.00 & 0.50 & $\mathrm{~S}$ \\
& 31 & 1.00 & 0.50 & $\mathrm{~S}$ \\
\hline
\end{tabular}

performed in rate that the value of absorbance is between 1.5 and 2.5.

The momentary precession of the reproduction is shown by the reproduction index with is product of absorbance and dilution. Worthy to know, that the index of reproduction can be used for identifying the algaculture's reproductional cycles and for guessing the order of magnitude of biomass concentrate.

It's able to compare cultures starting by the same conditions and to forecast the increase the concentrate of biomass.

To measure we need a photometer which can measure light absorbance on $681.5( \pm 0.5) \mathrm{nm}$. For sample taking measure with $20 \mathrm{~cm}^{3}$ is used because occasionally repeating is needed. By rating the reproduction’s index we need to consider the change of $\mathrm{pH}$.

The index of suspension can fluctuate day by day because of the change of environment. The $\mathrm{pH}$ of algacul- 
ture in good condition is between 7.5 and 8.5. If it differs, it forecast of an unusual event. If the $\mathrm{pH}$ and the index of reproduction decrease together it means that something undesired is in progress in the reactor.

The protocol using during the measure is shown by Figure 2.

Results of measure show us well that highly intensive reproduction started in the first 3 - 4 days of $\mathrm{CO}_{2}$ feed in the suspensions (Figure 3). By stop the feeding sudden settlement was salient.

We tried to follow the FCCD experiments up by weigh PCD. On Figure 4, it's easily seen that the change was very small-scale. The graphs are loaded with value wobbling and uneasiness.

The experiment put through, the samples settled. The effect can bring about, plural repeated. Without adequate analytics it can't be written down and so new trends to get.

For further use ability we need to expand new techniques.

We wrote up a new weigh method by using rectification of particles charge. The new technique can rid the faults mentioned before.

The residuary suspensions were splitted into more parts vertically. Under and under phase in normally, we made quotient by examinated particles charge with taking samples about $5 \mathrm{~cm}^{3}$ from phases. The quotient was named to relative particles charge reparation (RRTM).

Validation of weigh was made by absorbance and alga concentrate values of microalgae suspensions with variant attributes were connected with their RRTM. The samples were taken from under and upper phases of the examinated suspensions.

\section{Results}

In Table 3 we can see that we can't conclude well from the PCD values of the several suspensions (cor-

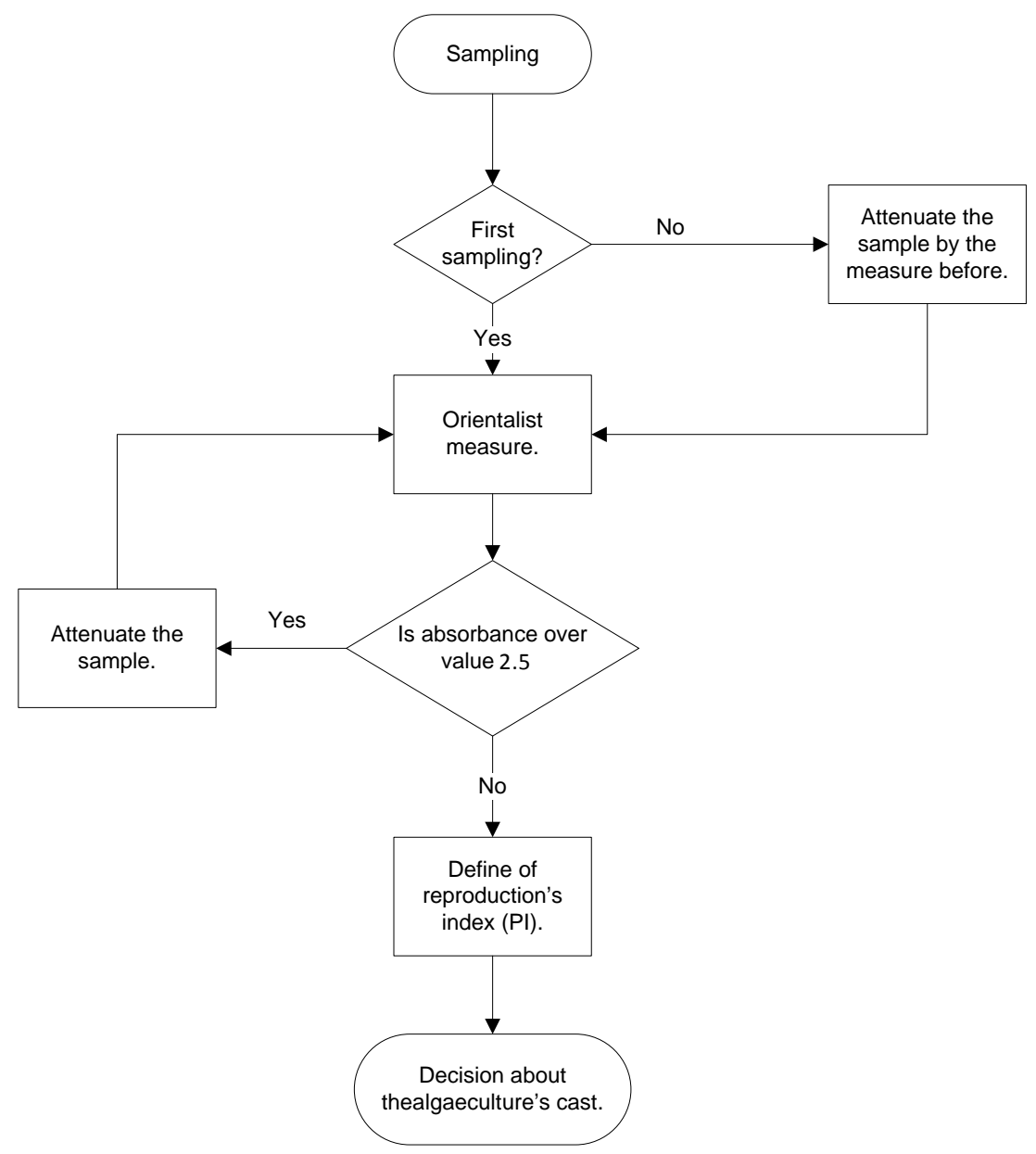

Figure 2. Method of reproduction's index determining. 


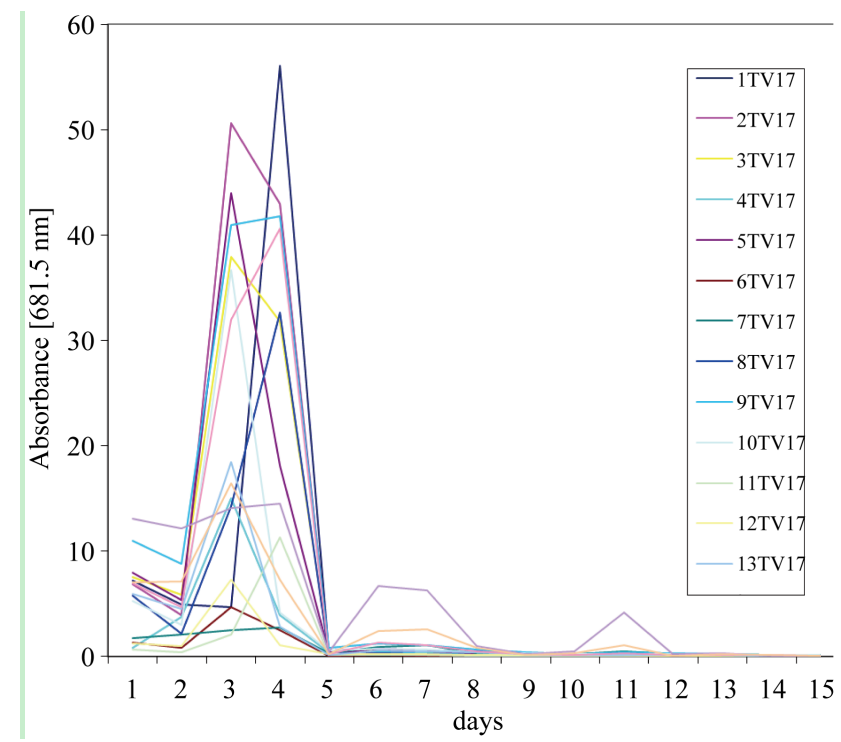

Figure 3. Value of ABS changing by time in experiment FCCD.

Table 3. Relative particles charge reparation (RRTM) method's validate measures synthesis.

\begin{tabular}{|c|c|c|c|c|c|c|}
\hline $\begin{array}{l}\text { Serial number } \\
\text { of suspension }\end{array}$ & $\begin{array}{l}\text { Suspension's } \\
\text { phase }\end{array}$ & $\mathrm{ABS}_{681.5}$ & $\begin{array}{c}\text { PCD } \\
q[\mu e q / g]\end{array}$ & $\begin{array}{c}\mathrm{C}_{\mathrm{alga}} \\
{\left[\mathrm{g} / \mathrm{dm}^{3}\right]}\end{array}$ & RRTM & Suspension attributes \\
\hline \multirow{2}{*}{1} & Upper & 6.0 & 198 & 3.2 & \multirow{2}{*}{1.0} & \multirow{2}{*}{ Homogen } \\
\hline & Under & 6.0 & 197 & 3.2 & & \\
\hline \multirow{2}{*}{2} & Upper & 0.7 & 244 & 1.3 & \multirow{2}{*}{1.3} & \multirow{2}{*}{ Small difference between two phases } \\
\hline & Under & 3.7 & 316 & 2.2 & & \\
\hline \multirow{2}{*}{3} & Upper & 0.2 & 98 & 0.1 & \multirow{2}{*}{2.1} & \multirow{2}{*}{$\begin{array}{l}\text { Two phases can be defined. upper light. } \\
\text { under dark green }\end{array}$} \\
\hline & Under & 6.4 & 201 & 3.8 & & \\
\hline \multirow{2}{*}{4} & Upper & 0.0 & 83 & 0.0 & \multirow{2}{*}{2.6} & \multirow{2}{*}{ Evident settlement. clear upper phase } \\
\hline & Under & 2.1 & 215 & 3.3 & & \\
\hline \multirow{2}{*}{5} & Upper & 0.4 & 126 & 0.2 & \multirow{2}{*}{2.5} & \multirow{2}{*}{ Evident settlement. clear upper phase } \\
\hline & Under & 6.9 & 314 & 4.8 & & \\
\hline \multirow{2}{*}{6} & Upper & 1.5 & 58 & 1.1 & \multirow{2}{*}{2.4} & \multirow{2}{*}{$\begin{array}{l}\text { Two phases can be defined. upper light. } \\
\text { under dark green }\end{array}$} \\
\hline & Under & 3.9 & 139 & 2.4 & & \\
\hline \multirow{2}{*}{7} & Upper & 0.0 & 80 & 0.1 & \multirow{2}{*}{3.6} & \multirow{2}{*}{ Evident settlement. clear upper phase } \\
\hline & Under & 1.2 & 287 & 0.8 & & \\
\hline \multirow{2}{*}{8} & Upper & 1.0 & 279 & 1.5 & \multirow{2}{*}{1.2} & \multirow{2}{*}{ Homogen } \\
\hline & Under & 1.2 & 335 & 1.6 & & \\
\hline \multirow{2}{*}{9} & Upper & 6.9 & 88 & 4.1 & \multirow{2}{*}{1.1} & \multirow{2}{*}{ Homogen } \\
\hline & Under & 6.9 & 97 & 4.0 & & \\
\hline \multirow{2}{*}{10} & Upper & 4.1 & 59 & 2.6 & \multirow{2}{*}{1.8} & \multirow{2}{*}{$\begin{array}{l}\text { Two phases can be defined. upper light. } \\
\text { under dark green }\end{array}$} \\
\hline & Under & 8.3 & 106 & 5.7 & & \\
\hline \multirow{2}{*}{11} & Upper & 0.2 & 46 & 0.0 & \multirow{2}{*}{2.8} & \multirow{2}{*}{ Evident settlement. clear upper phase } \\
\hline & Under & 9.9 & 129 & 8.9 & & \\
\hline & Upper & 1.3 & 248 & 0.5 & & \\
\hline 12 & Under & 1.3 & 273 & 0.5 & 1.1 & Homogen \\
\hline
\end{tabular}




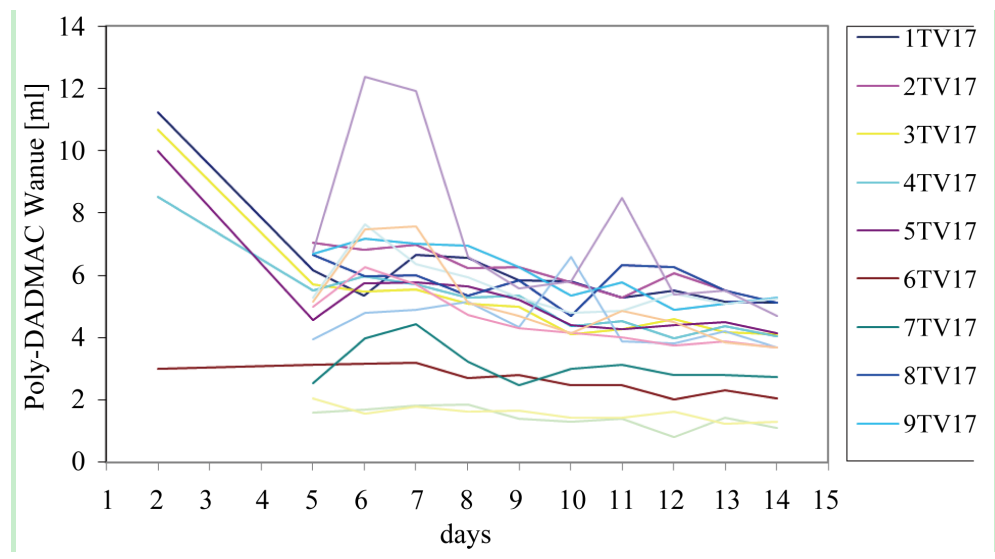

Figure 4. Poly-diallil-dimetil-ammonium-clorid wane values by experiment FCCD.

relate with each other). But the particles repartition in the suspension is well shown by absorbance and concentration value with RRTM from samples from one suspension (two phases). If RRTM is 2.5 or over, then it suggests disunity.

Therefore we had chance to observe more exactly the settlement and write it off scientifically. The new technique is suited to detect the settlement numerical and to stipulate the optiamal parameters' of settlement.

\section{Acknowledgements}

This research was supported by the European Union and the State of Hungary, co-financed by the European Social Fund in the framework of TÁMOP 4.2.4. A/2-11-1-2012-0001 "National Excellence Program".

\section{References}

[1] Doucha, J., Straka, F. and Lívansky, K. (2005) Utilization of Flue Gas for Cultivation of Microalgae (Chlorella sp.) in an Outdoor Open Thin-Layer Photobioreactor. Journal of Applied Phycology, 17, 403-412. http://dx.doi.org/10.1007/s10811-005-8701-7

[2] Olaizola, M. (2003) Microalgal Removal of $\mathrm{CO}_{2}$ from Flue Gases: Changes in Medium pH and Flue Gas Composition Do Not Appear to Affect the Photochemical Yield of Microalgal Cultures. Biotechnology and Bioprocess Engineering, 8, 360-367. http://dx.doi.org/10.1007/BF0294928

[3] Pedroni, P.M., Lamenti, G., Prosperi, G., Ritorto, L., Scolla, G., Capuano, F. and Valdiserri, M. (2005) Enitecnologie $\mathrm{R} \& D$ Project on Microalgae Biofixation of $\mathrm{CO}_{2}$ : Outdoor Comparative Tests of Biomass Productivity Using Flue Gas $\mathrm{CO}_{2}$ from a NGCC Power Plant. The 7th International Conference on Greenhouse Gas Control Technologies, 2, 10371042. http://dx.doi.org/10.1016/B978-008044704-9/50105-1

[4] Carlsson, A.S., Bilen, J.B., Möller, R. and Clayton, D. (2008) Mircro- and Macroalgae: Utility for Industrial Applications. In: Bowles, D., Ed., Outputs from the EPOBIO Project, CPL Press, Berks.

[5] Vasudevan, P.T. and Briggs, M. (2008) Biodiesel Production-Current State of the Art and Challenges. Journal of Industrial Microbiology \& Biotechnology, 35, 421-430. http://dx.doi.org/10.1007/s10295-008-0312-2

[6] Hwang, E.J., Shin, H.S. and Chae, S.R. (2006) Single Cell Protein Production of Euglena Gracilis and Carbon Dioxide Fixation in an Innovative Photo-Bioreactor. Bioresource Technology, 97, 322-329. http://dx.doi.org/10.1016/j.biortech.2005.02.037

[7] Becker, E.W. and Baddiley, J. (1994) Microalgae: Biotechnology and Microbiology. Cambridge University Press, Cambridge, Inc., New York.

[8] Posewitz, M.C., Jinkerson, R.E. and Subramanian, V. (2011) Improving Biofuel Production in Phototrophic Microorganisms with Systems Biology Tools. Biofuels, 2, 125-144. http://dx.doi.org/10.4155/bfs.11.7

[9] Horváth, G., Hanák, L. and Bocsi, R. (2010) Microalgae Production in Service of Fuel Production. Hungarian Journal of Industrial Chemistry, 38, 9-13. http://konyvtar.uni-pannon.hu/hjic/HJIC38_009_013.pdf

[10] Shelef, G.A., Sukenik, A. and Green, M. (1984) Microalgae Harvesting and Processing: A Literature Review. Technical Report, Solar Energy Research Institute. http://dx.doi.org/10.2172/6204677 
[11] Poelman, E., Pauw, N.D. and Jeurissen, B. (1997) Potential of Electrolytic Flocculation for Recovery of Micro-Algae, Resources Conservation and Recycling, 19, 1-10. http://dx.doi.org/10.1016/S0921-3449(96)01156-1

[12] Leite, G.B., Abdelaziz, A.E.M. and Hallenbeck, P.C. (2013) Algal Biofuels: Challenges and Opportunities. Bioresource Technology, 145, 134-141. http://dx.doi.org/10.1016/j.biortech.2013.02.007

[13] Becker, E.W. and Wolfgang, E. (1994) Microalgae: Biotechnology and Microbiology. Cambridge University Press, Cambridge, 153-154.

[14] Sukenik, A. and Shelef, G. (1984) Algal Autoflocculation-Verification and Proposed Mechanism. Biotechnology and Bioengineering, 26, 142-147. http://dx.doi.org/10.1002/bit.260260206

[15] Salim, S., Shi, Z., Vermuë, M.H. and Wijffels, R.H. (2013) Effect of Growth Phase on Harvesting Characteristics, Autoflocculation and Lipid Content of Ettlia Texensis for Microalgal Biodiesel Production. Bioresource Technology, 138, 214-221. http://dx.doi.org/10.1016/j.biortech.2013.03.173

[16] Clavero, S.S.E. and Salvadó, J. (2013) Potential Pre-Concentration Methods for Nannochloropsis Gaditana and a Comparative Study of Pre-Concentrated Sample Properties. Bioresource Technology, 132, 293-304. http://dx.doi.org/10.1016/j.biortech.2013.01.037

[17] Wan, C., Zhao, X.-Q., Guo, S.-L., Asraful, A. and Bai, F.-W. (2012) Bioflocculant Production from Solibacillus Silvestris W01 and Its Application in Cost-Effective Harvest of Marine Microalga Nannochloropsis Oceanica by Flocculation. Bioresource Technology, 135, 207-212. http://dx.doi.org/10.1016/j.biortech.2012.10.004

[18] Guo, S., Zhao, X., Wan, C., Huang, Z.-Y., Yang, Y.-L., Asraful Alam, Md., Ho, S.-H., Bai, F. and Chang, J.-S. (2013) Characterization of Flocculating Agent from the Self-Flocculating Microalga Scenedesmus Obliquus AS-6-1 for Efficient Biomass Harvest. Bioresource Technology, 145, 285-289. http://dx.doi.org/10.1016/j.biortech.2013.01.120

[19] Jimin, L., Dae-Hyun, C., Rishiram, R., Byung-Hyuk, K., Hee-Mock, O. and Hee-Sik, K. (2013) Microalgae-Associated Bacteria Play a Key Role in the Flocculation of Chlorella Vulgaris. Bioresource Technology, 131, 195-201. http://dx.doi.org/10.1016/j.biortech.2012.11.130

[20] Dong-Geol, K., Hyun-Joon, L., Chi-Yong, A., Yong-Ha, P. and Hee-Mock, O. (2011) Harvest of Scenedesmus sp. with Bioflocculant and Reuse of Culture Medium for Subsequent High-Density Cultures. Bioresource Technology, 102, 3163-3168. http://dx.doi.org/10.1016/j.biortech.2010.10.108

[21] Rawat, I., Ranjith Kumar, R., Mutanda, T. and Bux, F. (2013) Biodiesel from Microalgae: A Critical Evaluation from Laboratory to Large Scale Production. Applied Energy, 103, 444-467. http://dx.doi.org/10.1016/j.apenergy.2012.10.004 